\title{
O Corpo-Horizonte: sobre Miragens de Regina de Paula
}

Tania Rivera*

RESUMO: Este ensaio problematiza a presença do corpo na arte contemporânea, defendendo que se trata, no que diz respeito ao corpo, principalmente de desconfiar de sua própria casa e pôr em questão sua ligação ao Eu. Em um diálogo com a artista Regina de Paula, especialmente sua instalação Miragem, realizada em 2012 na Casa França-Brasil, no Rio de Janeiro, tenta-se demonstrar o poder que o corpo possui de transformar o espaço e pôr em cena o desejo, e argumentar que é muitas vezes necessário que o corpo se faça ausente-mesmo, eventualmente, que ele se dê a ver - para que assim se transforme em um lugar vacante no qual o olhar possa efemeramente se alojar.

Palavras-chave: Regina de Paula; corpo; Eu; espaço; olhar; psicanálise

ABSTRACT: This essay reflects about the presence of the body in contemporary art, in order to argue that more than to simply affirm itself, the body is able to distrust its own home and to problematize its bond with the self. Intertwining a dialogue with Regina de Paula's work, specially the installation Miragem (Mirage), exhibited in Casa França-Brasil in 2012, we intend to show the power of the body to transform space and to bring desire into the scene, as well as to affirm that the body shall often be absent - even when it is shown - in order to turn itself onto a vacant place in which the viewer's gaze could ephemerally lodge.

Keywords: Regina de Paula; body; self; space; gaze; psychoanalysis

\footnotetext{
*Tania Rivera é mestre e doutora em Psicologia pela Université Catholique de Louvain (1996). Realizou pós-doutorado em Artes Visuais na EBA-UFRJ (2006). Foi professora da Universidade de Brasília de 1998 a 2010 e atualmente é professora da Universidade Federal Fluminense.
} 
Miragens é uma instalação realizada na Casa França-Brasil em 2012, no exíguo espaço que durante séculos foi o cofre da Alfândega. Regina de Paula delimitou a área deste recinto de cerca de $1,5 \mathrm{~m}$ de lado e quase $4 \mathrm{~m}$ de altura, subtraindo aquela utilizada pela porta que abre para o interior, com uma parede de acrílico que ia do chão até a exata altura de seus olhos, e preencheu com uma tonelada de areia o espaço assim formado entre o muro curvo e transparente e as paredes de alvenaria.

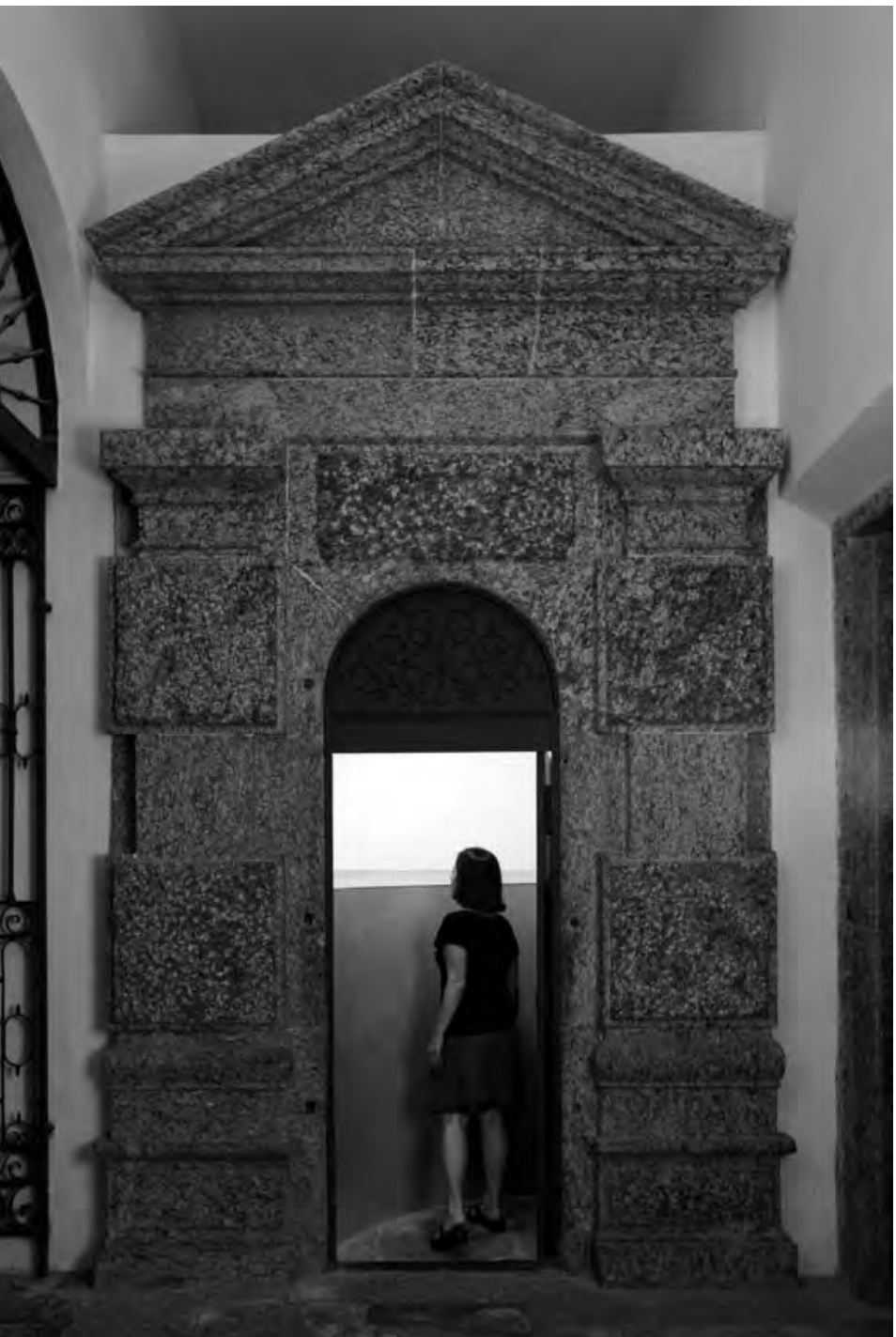




\section{Regina de Paula}

Miragens, 2012

instalação no cofre da Casa França-Brasil areia contida por placa de acrílico

Foto: Wilton Montenegro

O corpo da artista não está diretamente presente no trabalho, mas faz parte dele de modo fundamental. Ele estabelece o lugar do olhar que transforma aquela superfície arenosa diminuta em outra coisa: o espaço infinito do horizonte, derrubando as imponentes paredes do prédio neoclássico para jogar-nos em um lugar mágico e incerto. “É o meu olhar, é a minha escala", diz Regina. No instante em que aceito o convite a ocupar com meu corpo esse lugar vacante inscrito pela artista, apresenta-se diante de mim uma enorme vastidão, como se, 
em uma miniaturização do mundo (e de meu corpo), eu estivesse frente a um deserto (como sugere também o poético título Miragens). E no deserto, como bem sabem mesmo aqueles que jamais caminharam sobre suas dunas, abre-se o espaço mágico das miragens. Do desejo.

As belas imagens feitas por Wilton Montenegro registram a instalação mas falham em mostrar a vivência espacial (e imaginária, desejante) de que se trata, pois o dispositivo fotográfico só pode achatar a distância e trazer nosso olhar de volta à superfície. Porém, elas fazem outra coisa muito interessante e surpreendente: revelam um jogo geométrico que dialoga com a tradição concreta e neoconcreta e, especialmente, com a ideia de "linha orgânica", primordial na obra de Lygia Clark. Para esta, a linha que surge entre quadro e moldura quando ambos são da mesma cor seria "orgânica", ou seja, teria algo a ver com o corpo. Explorando essa descoberta, Clark tentou, durante alguns anos a partir de 1954, "arrebentar o núcleo do quadro (tela) levando a cor desta para a moldura", abrindo assim o que ela classifica de "espaço liberto". (CLARK, 1999/1959, p. 83) Por meios diferentes, é dessa mesma libertação poética dos espaços que trata Miragens.

Regina de Paula realizou com Miragens a façanha de construir um horizonte.

Um horizonte não se estabelece tão facilmente quanto poderia parecer. Não basta fixar a linha horizontal onde termina o mar, ou a linha acidentada do contorno dos prédios ou dos morros contra o céu. O perfil de nosso campo de visão, uma vez fixado em desenho, deixa de ser horizonte para se tornar paisagem. O horizonte só se define como o limite do olhar. Ele está, portanto, sempre em movimento, delineando-se exclusivamente em relação à posição ocupada pelo olhador no espaço. Mas isso não quer dizer que seja possível medir a distância entre seus olhos e o horizonte. Trata-se de um espaço sempre móvel que o olhador jamais poderá atingir: ele está sempre além. No entanto, ele está sempre presente, ainda que não seja visível em um dado momento.

A paisagem organiza perspectivamente, a partir de um ponto de vista bem estabelecido, distâncias e relações entre os elementos visíveis. Em vez deste ponto de vista rigidamente fixado de modo a fornecer as medidas da composição pictórica, Miragens agencia um lugar do olhar, um espaço difuso que está fora do campo visual e, no entanto, se faz presente no espaço incomensurável (orgânico, diria Clark) aberto entre ele e o horizonte. 
E talvez esse lugar, uma vez estabelecido, sutilmente pontuado em um trabalho artístico, constitua a presença do corpo em sua máxima potência, mais efetiva do quando ele aparece em figura no campo visual (seja como representação do corpo ou apresentação do corpo real em performances, fotografias etc.). Afinal, a nossa vivência do corpo é marcadamente aquela do olhar (em combinação com a dos outros sentidos que podem tomar a frente no caso de uma deficiência de visão). A vivência de meu corpo é aquela do lugar que ocupo em relação a um horizonte sempre móvel. Por isso nunca estou inteiramente presente na imagem do meu corpo, seja ela dada pelo espelho ou pela fotografia. Meu corpo é o que vejo mal, vejo fragmentariamente, pois ele é o lugar do qual vejo o mundo. Ao contrário do olho fixo (e único) que guia a construção perspectiva fornecendo-lhe a marcação do ponto de fuga, o lugar do olhar é móvel e instável ("Instável no espaço, parece que estou me desagregando. Viver a percepção, ser a percepção..., diz ainda Lygia Clark (CLARK, 1999/1965, p. 164)).

Meu corpo é o contraponto do horizonte.

É por uma operação topológica que Miragens transforma o espaço arquitetônico, solidamente organizado pelas leis da geometria, naquilo que Deleuze e Guattari denominam "espaço liso". Em vez do esquadrinhamento, da medição geográfica e da lógica cartográfica que definem o espaço "estriado" de nossas plantas arquitetônicas e mapas, que ordenam o mundo em retas mensuráveis e trajetórias fixas e estabelecem uma firme localização a nossos corpos, o "espaço liso" seria aquele das travessias incertas que só a fortiori estabelecem seus pontos de passagem, aquele espaço amorfo feito mais de volume do que de desenho, como o mar (sem o recurso às cartas marítimas ou à utilização da astronomia) e o deserto. Espaço sem limites, aberto à mobilidade, a travessias infinitas, em todas as direções. Marcado apenas por sutis diferenças, o que o ocupa são "as intensidades, os ventos e ruídos, as forças e as qualidades táteis e sonoras, como no deserto, na estepe ou no gelo". (DELEUZE e GUATTARI, 1997/1980, p. 185)

No espaço estriado, o corpo ocupa alguma firme posição, um ponto distinto de todos os outros pontos (como o olho fixo da perspectiva). Já no espaço liso ele joga com o espaço e quase se conjuga a ele. Mas não se trata, neste último, de um espaço plácido a alojar um corpo imóvel. Trata-se de um espaço móvel como a areia do deserto a deslocar-se em dunas (e 
eventualmente a nos cegar os olhos). Trata-se de um território em constante reconfiguração, mas que sempre apresentará um horizonte - e, graças a ele, em relação a ele, dará ao sujeito algum efêmero lugar.

Os primeiros trabalhos com a areia surgiram das frequentes caminhadas de Regina de Paula pela praia de Copacabana, nos anos 1990, período de seu retorno ao Brasil após uma temporada nos Estados Unidos. Com o olhar estranhado de quem volta a seu habitat, Regina percebeu que "tinha que trabalhar com aquela matéria": a areia. Ela se pôs então a "construir com a areia". Primeiro vieram os tijolos, em seguida os pequenos castelos de areia feitos com um molde de brinquedo infantil em formato tradicional. A expressão "castelos de areia", comum entre nós, faz com que essas delicadas construções abriguem todos os sonhos, todas as miragens.

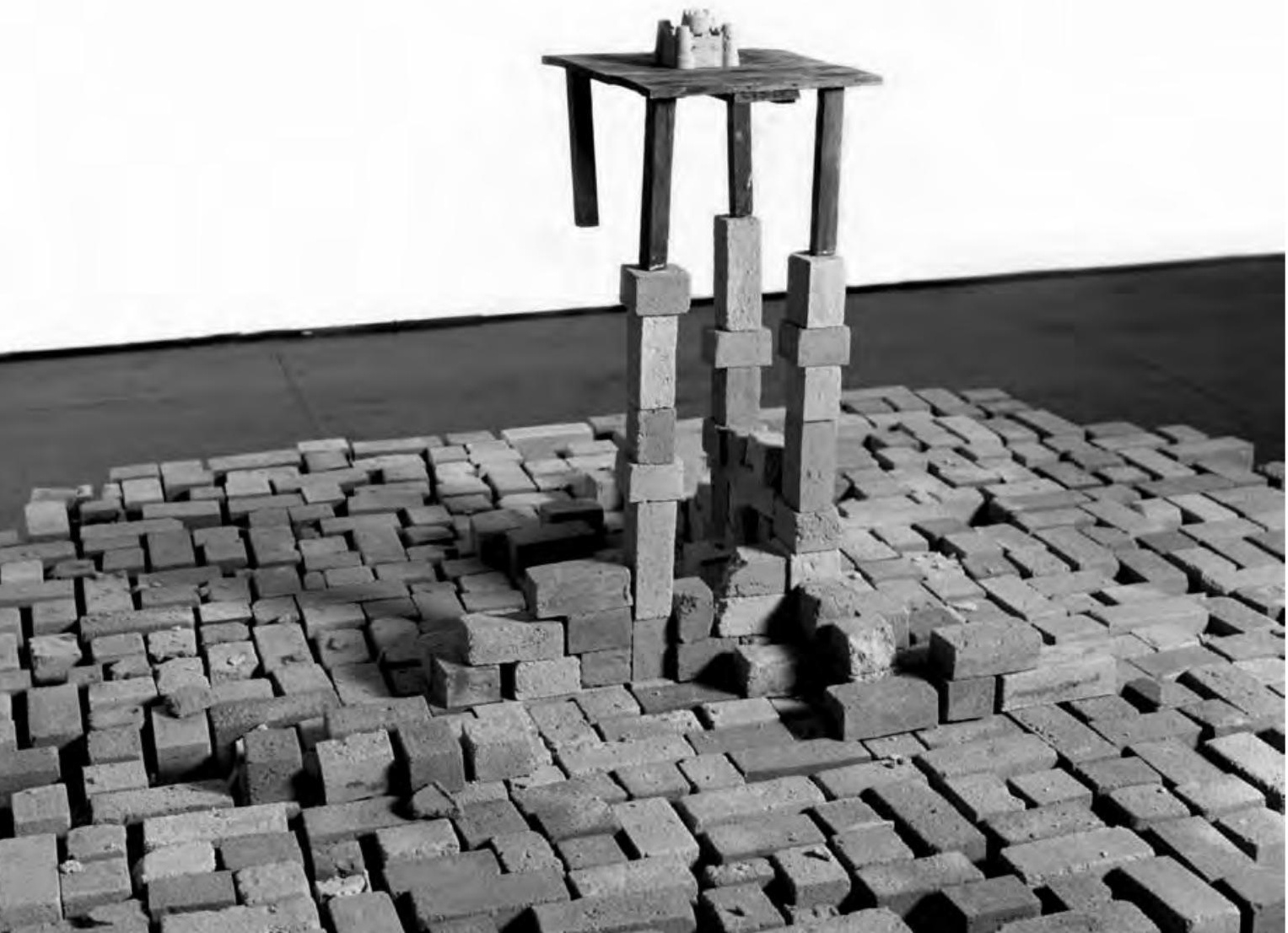

Regina de Paula Sem título, 1997. tijolos de areia e madeira $92 \times 225 \times 310 \mathrm{~cm}$ (variável) Foto: Wilton Montenegro 
Em exposição no Salão Nacional do MAM-Rio em 1997, um desses castelos encontrava-se em cima de uma mesa de pernas tortas (que a artista encontrou em um quiosque à beira-mar no litoral fluminense). A mesa equilibra-se precariamente sobre apenas três colunas de tijolos de areia. Junto ao chão, tijolos semidesfeitos e um pouco de areia solta, esparramada (Sem Título, 1997). Na exposição Cubo-paisagem, em 2009 no Parque Lage, a artista fez com tijolos do mesmo tipo um cubo de 1,20m de lado. Esse cubo de geometria exata parece homenagear o minimalismo (esse elogio ao espaço estriado), ao mesmo tempo em que introduz nele a precariedade e a abertura imaginária do espaço liso: no centro superior, a geometria se desmancha e surge, no lugar de um dos tijolos, um castelinho de areia. O cubo expande-se em paisagem, como afirma seu título, ao mesmo tempo em que critica e desmancha a ideia de composição paisagística em prol de uma transformação do espaço e do sujeito. Cubo-mundo. Horizonte mágico.

Regina de Paula

Sem Título (Cubo Paisagem), 2009. técnica mista com areia

$120 \times 120 \times 120 \mathrm{~cm}$

instalação nas Cavalariças da Escola de Artes Visuais do Parque Lage Foto: Wilton Montenegro

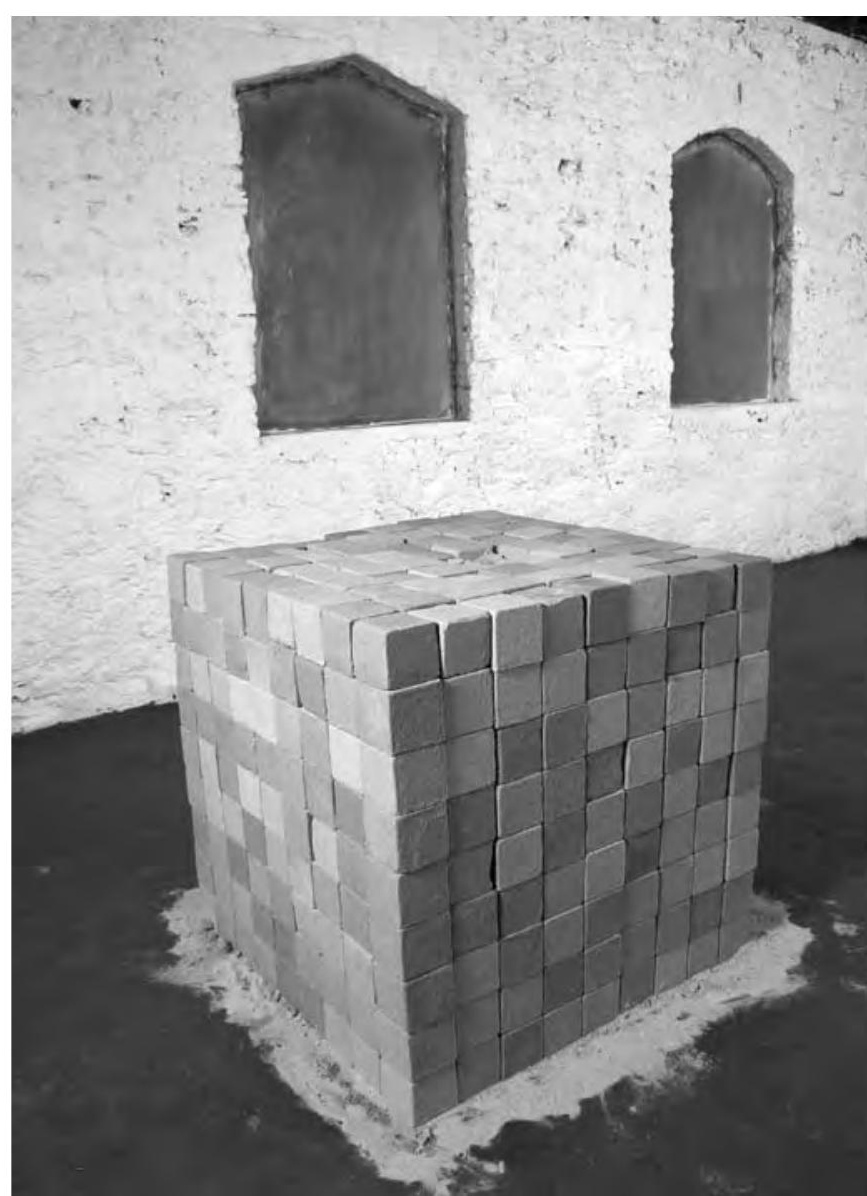


Além de ser mutável, o espaço liso recusa-se a nos oferecer um chão firme. Como as ondas de um mar revolto, a areia também pode fender-se, resistindo a nossos passos e transformando-se sob nosso peso. Ela cede e pode gerar deslizamentos e fendas. Areia movediça.

Regina conta que durante a montagem de Miragens apareceram bruscas e profundas fendas, enquanto a areia era derramada no espaço delimitado pelo acrílico. Além disso e um tanto misteriosamente, a areia jamais chegava ao nível desejado, fazendo que se supusesse haver alguma brecha invisível no solo, pela qual parte dela escapava insidiosamente. 
Robert Smithson, importante representante da Land Art, afirma que

A mente e a terra estão num constante estado de erosão. Rios mentais desgastam margens abstratas, ondas cerebrais escavam rochedos de pensamento, ideias se decompõem em pedras de desconhecimento e cristalizações conceituais se fragmentam em depósitos de razão arenosa. (SMITHSON, 2006/1968, p. 182)

É difícil pensar o corpo correspondente a tal erosão, a tal "razão arenosa". Se a terra está alegoricamente no lugar da "mente" de que fala Smithson, é na medida em que essa mente faz-se corpo, materializa-se em perda e transformação. Talvez o corpo, a fronteira pela qual participamos do mundo, esteja constantemente em atrito e erosão, mas também seja lugar de depósito e acumulação de elementos móveis e sutis. E como o corpo vivido é, sobretudo, o lugar do olhar, ele se mostra fora: na terra.

Portanto, não basta trazer o corpo do artista para dentro do trabalho artístico, seja em performances ou em trabalhos que registrem de alguma maneira sua presença, para que ele efetivamente se faça valer em sua potência arenosa, digamos, que já está fora dela mesma. Apresentar um corpo não é simplesmente afirmá-lo, mas dar lugar à questão que o define - e que é capaz de transformar o espaço.

O corpo visado pela reflexão artística contemporânea desconfia de sua própria casa e põe em questão (em erosão) a identidade entre o eu e o corpo. Freud não fazia outra coisa ao afirmar que "o eu não é mais senhor em sua própria casa" (seja ela o corpo ou o mundo). Paradoxalmente talvez seja necessário, para evocar a força corporal capaz de transformar o espaço e evocar o desejo, que o corpo se faça ausente - mesmo, eventualmente, que ele se dê a ver - e se transforme em lugar vacante no qual o corpo do olhador, ou seja, seu olhar, possa efemeramente se alojar.

O conhecido texto de Freud O Estranho trata justamente do surgimento dessa potência de convocação do olhar graças a uma problematização da imagem do corpo. (FREUD, 1986/1919) O psicanalista conta nesse texto um episódio de estranhamento vivido por ele próprio em uma viagem de trem. Devido a um brusco solavanco, a porta espelhada de seu compartimento abriu-se e ele não reconheceu nela o reflexo de seu próprio corpo, acreditando tratar-se de um estranho. Essa história um tanto banal pode nos servir de modelo: é quando se entreabre o firme laço que nos une à nossa imagem corporal que se pode apresentar o corpo-olhar, o corpo vivido pelo qual olhamos o mundo em nossa condição de sujeitos. 
O texto literário que ajuda Freud a elaborar seu conceito de estranho (unheimlich) é, curiosamente para nossos propósitos aqui, um conto de E. T. A. Hoffmann que trata da areia e do olhar: "O Homem de Areia". (HOFFMANN, 1980/1917) O título refere-se ao personagem que, em histórias contadas às crianças, jogaria areia nos olhos destas e ameaçaria arrancar-lhes os olhos caso elas não fossem dormir na hora certa. A areia parece servir aí para embaçar a visão (como faz o sono) e abrir o campo do olhar em toda sua potência ficcional que é aquela do sonho, diga-se de passagem). O duplo, a imagem do corpo então se estranha e faz surgir a disjunção entre a imagem do corpo e a presença de um sujeito. Os autômatos, bonecos semelhantes ao homem, frequentemente aparecem para evocar tal disjunção na literatura fantástica do século XIX, colocando implicitamente a pergunta: um corpo, será ele alguém? No conto de Hoffmann, Ofélia fascina o ingênuo estudante Nataniel, que não cessa de olhá-la. Mas essa boneca carrega algo de inquietante que ameaça o rapaz e pode levá-lo à morte.

Trata-se no estranho, assim, de uma problematização do corpo que incita o surgimento do corpo-olhar. Freud não chega a considerar a questão do espaço em sua teorização do Estranho, mas o texto de 1906 que lhe serviu de incitação para refletir sobre a estranheza, "Sobre a Psicologia do Estranho", de Ernst Jentsch, toma o conceito como uma "falta de orientação" frente ao mundo. (JENTSCH, 1906, p. 195) Freud menciona este fator, de passagem, como parte da contribuição de seu predecessor: "quanto mais orientada uma pessoa estiver em seu ambiente (Umwelt), menos facilmente ela receberá das coisas ou eventos que aí se produzem a impressão de estranheza." (FREUD, 1955/1919, p. 231) Ali onde o espaço liso se entreabre e desorienta o eu, o corpo se põe em questão e o sujeito (do inconsciente, do desejo) é convidado a surgir e habitar estranhamente o mundo.

A própria arquitetura pode, na proposta de Regina de Paula, revirar-se em território-convite a um desalojamento capaz de estranhar o eu e o mundo. Como em Miragens, nunca se apresenta um corpo nas fotografias da série Não-Habitável (1999). Mas toda fotografia materializa o olhar da artista, carregando sua passagem, sua presença pretérita nesse ambiente. As primeiras imagens da série foram tiradas em Nova York, no corredor subterrâneo do alojamento em que a artista vivia, lugar deserto que ela descobriu consistir em uma passagem para o prédio da universidade. Um díptico da série apresenta um espelho de segurança refletindo outro espelho de segurança no outro canto desse corredor e vice-versa. A apresentação dessas duas fotos lado a lado constrói uma louca e impossível passagem, um lugar no qual não há 
ninguém (nenhum espelho captura a imagem da fotógrafa), mas que estranhamente solicita algum corpo. Trata-se de uma espécie de armadilha para pegar meu corpo, meu olhar.

Na série Não-Habitável SSCC (que se iniciou em 1999, utilizando imagens feitas em 1989), Regina de Paula capta imagens de um conhecido centro comercial próximo de sua residência, o chamado Shopping dos Antiquários, que ela já frequentava muito antes de pensar em incluí-lo em seu trabalho. "Preciso ter um encontro com o lugar", diz ela, salientando que quase todas as suas fotografias são de espaços que ela vivencia: "sou eu dentro do meu espaço". Como o título indica, as fotografias e o vídeo que fazem parte de Não-Habitável SSCC não estão habitadas: não se vê ninguém nos corredores pelos quais durante o dia costuma passar uma quantidade considerável de gente. A não-habitação, a ausência de um corpo visível, é justamente o que permite que se apresente nessas imagens o olhar da artista a habitar o mundo. Pode então se apresentar o corpo-horizonte, ganhando o mundo e revirando a arquitetura - posto que, como diz Regina relatando algo que alguém Ihe teria dito e que a encanta: "o espaço é a gente."

\section{Notas}

1 Ver http://www.york.cuny.edu/ malk/tidbits/n-cube-tidbit.html

\section{Referências}

CLARK, Lygia. Lygia Clark e o Espaço Concreto Expressional (1959). Lygia Clark. Rio de Janeiro: Paço Imperial/Minc IPHAN, 1999, p. 83-86.

CLARK, Lygia. Do Ato (1965). Lygia Clark. Rio de Janeiro: Paço Imperial/Minc IPHAN, 1999, p. 164-165.

DELEUZE, Gilles e GUATTARI, Félix (1980). Mil Platôs. Capitalismo e Esquizofrenia, vol. V. São Paulo: Editora 34, 1997.

FREUD, Sigmund (1919). Das Unheimliche. Gesammelte Werke. Vol. XII. Londres: Imago, 1955, p. 229-268.

HOFFMANN, Ernst Theodor Amadeus (1917). L'Homme au Sable. Contes Fantastiques. Paris: Flammarion, 1980.

JENTSCH, Ernst. Zur Psychologie des Unheimlichen. Psychiatrisch-Neurologische Wochenschrift, n. 22, agosto de 1906. 